\title{
Rancang Bangun Sistem Telemetri Pengukur Konsentrasi Gas Amonia Menggunakan Sensor MQ-137 dan Transceiver nRF24L01+
}

\author{
Eriyaldi*, Wildian \\ Jurusan Fisika, FMIPA, Universitas Andalas, Kampus Limau Manis Padang, 25163 \\ *eriyaldi47@gmail.com
}

\begin{abstract}
ABSTRAK
Telah dilakukan perancangan sistem telemetri untuk mengukur konsentrasi gas amonia. Rancangan perangkat keras sistem terdiri dari satu unit transmitter dan receiver. Semua unit dikontrol oleh microcontroler Atmega328. Data konsentrasi gas dikirim oleh unit transmitter ke unit receiver menggunakan transceiver nRF24L01+ yang memanfaatkan gelombang radio sebagai media pengirim. Sensitivitas sensor yang didapatkan dari pengujian sensor MQ-137 yaitu sebesar 0,0208 V/ppm. Pengujian transceiver nRF24L01+ pada kondisi tanpa penghalang atau Line of Sight (LOS) diperoleh jarak maksimum sebesar $599 \mathrm{~m}$. Intensitas gelombang pada kondisi dengan penghalang atau Non Line of Sight (NLOS) mengalami atenuasi sehingga jangkauan transmisi nRF24L01+ berkurang.

Kata kunci: gas amonia, sensor MQ-137, telemetri, tranceiver nRF24L01+, LOS dan NLOS
\end{abstract}

\section{ABSTRACT}

In this research, the telemetry system for measurement of ammonia gas concentration was designed. Hardware system consists of a transmitter and a receiver unit. All units of the system are controlled by Atmega328 microcontroler. The concentration data of ammonia gas were sent by transmitter unit to receiver unit using $n R F 24 L 01+$ transceiver that used radio waves as delivery medium. The sensitivity of sensor resulted by the characterization of MQ-137 sensor was $0.0208 \mathrm{~V} / \mathrm{ppm}$. The nRF24L01+ transceiver transmitted data with a maximum propagation distance of $599 \mathrm{~m}$ in line of Sight (LOS) condition. The wave intensity of $n R F 24 L 01+$ was attenuated by obstacle, the maximum propagation distance would decrease.

Keywords: Ammonia gas, MQ-137 sensor, wireless telemetry, nRF24LO1+ transceiver, LOS and NLOS

\section{PENDAHULUAN}

Limbah gas amonia dari industri yang terlepas ke udara perlu diperhatikan. Hal ini harus ditangani dengan serius, agar proses produksi bisa menguntungkan dan menjaga lingkungan. Penjagaan lingkungan pabrik dari polusi gas amonia membutuhkan pemantauan khusus. Masalah ini akan mengganggu proses produksi di Industri dan proses pemantauanpun tidak dapat berjalan dengan baik. Penanganan khusus guna mencegah dampak negatif yang dapat ditimbulkan oleh gas amonia pada suatu industri perlu dilakukan. Penanganan ini dapat direalisasikan dengan melakukan riset dan penelitian.

Beberapa penelitian tentang rancang bangun alat ukur konsentrasi gas telah dilakukan, antara lain Permana dkk. (2011) telah melakukan pengembangan alat deteksi gas pada tambang batubara bawah tanah dengan sistem kabel dan telemetri. Penelitian tersebut memiliki kekurangan yaitu masih menggunakan kabel data $1000 \mathrm{~m}$ untuk menghubungkan ke repeaternya. Pramono dkk. (2015) juga telah merancang alat telemetri temperatur dan gas pada gunung berapi secara wireless. Pada penelitian ini didapatkan temperatur yang diukur dapat mencapai $500{ }^{\circ} \mathrm{C}$ dan kadar gas $\mathrm{CO}$ sampai $10.000 \mathrm{ppm}$ dan dapat dikirim sejauh 7,4 km menggunakan Handy Talky (HT). Biaya yang besar juga menjadi kendala utama dari penelitianpenelitian tersebut.

Berdasarkan kendala-kendala di atas maka perlu dilakukan pemilihan modul transceiver dalam merancang sistem telemetri nirkabel. Terdapat banyak jenis transceiver yang dikembangkan saat ini, beberapa yang sering digunakan para perancang adalah modul transceiver nRF24L01+ dan modul Xbee Pro. Penelitian ini merancang sistem telemetri wireless nRF24L01+ konsentrasi gas amonia secara realtime. Pemilihan nRF24L01+ karena memiliki data rate, stabilitas, akurasi dan toleransi yang lebih baik dibanding Xbee Pro (Fajriansyah dkk., 2016). Selain itu, jangkauan transmit data modul ini dapat mencapai jarak maksimum $1000 \mathrm{~m}$ (Docfoc, 2016). Sensor yang digunakan adalah MQ-137 yang diproses oleh microcontroler Atmega328, data akan disimpan pada PC. 


\section{METODE}

\subsection{Perancangan diagram blok sistem}

Rancangan sistem telemetri nirkabel pengukuran konsentrasi ini diawali dengan penginderaan besaran konsentrasi gas/objek oleh sensor MQ-137. Keluaran sensor ini berupa tegangan digital yang kemudian akan diteruskan ke Arduino UNO R3. Diagram blok sistem untuk perancangan perangkat keras yang akan dibangun dalam penelitian ini adalah seperti pada Gambar 1. Modul nRF24L01+ pada bagian transmitter (TX) yang telah menerima data dari Arduino Uno R3 akan memodulasikan sinyal digital tersebut pada gelombang radio dan mengirimkan data tersebut ke bagian receiver $(\mathrm{RX})$. Selanjutnya, pada receiver data yang telah diterima akan diolah kembali oleh Arduino Uno R3 dan masuk ke personal computer untuk disimpan.
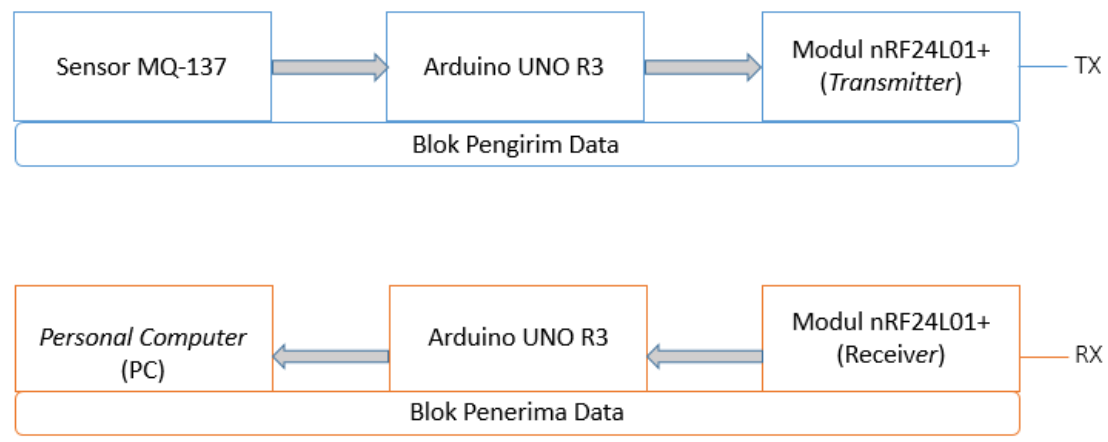

Gambar 1 Diagram Blok Sistem

\subsection{Pengujian Sensor MQ-137}

Proses pengujian ini dilakukan dengan menghubungkan rangkaiaan Arduino UNO R3 dengan sensor MQ-137. Sensor MQ-137 memiliki 6 pin, yaitu 2 buah pin H (heating electrodes), 4 pin buah pin testing electrodes yang terdiri dari 2 pin A, 2 pin B. Pin A terhubung ke pin A ketika pin B terhubung ke pin B. Pin-pin ini akan membuat lead rusak jika dihubungkan dengan tegangan secara bersamaan. Hal ini akan menimbulkan tidak ada sinyal output yang diterima di pin 2 dan 4. Pin-pin ini akan dihubungkan ke port A0 pada Arduino UNO R3. Skematik rangkaian alat dapat dilihat pada Gambar 2.

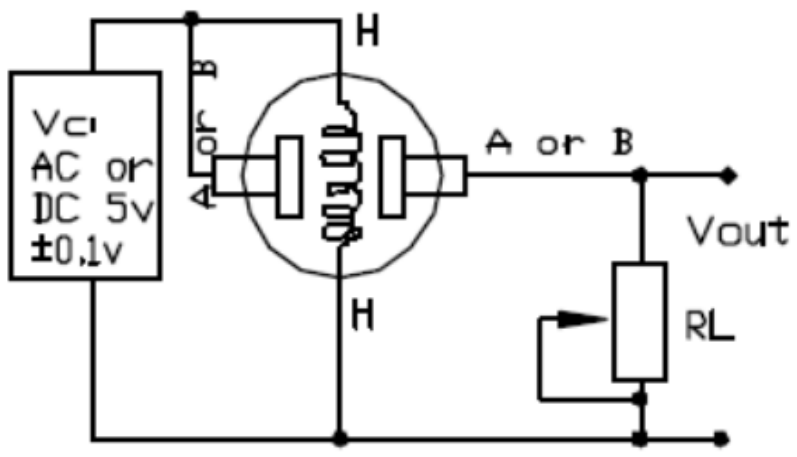

Gambar 2 Skematik Rangkaian Alat

Proses pengujian sensor MQ-137 dimulai dengan melakukan variasi konsentrasi. Variasi konsentrasi pada pengujian ini dilakukan dengan memasukkan $0,5 \mathrm{~mL}$ cairan amonia 1 M yang dilarutkan dengan $50 \mathrm{~mL}$ aquabides ke dalam gelas ukur. Hal ini dilakukan untuk memperlambat laju penguapan amonia. Larutan amonia ini dan ammonia gas meter (dalam keadaan hidup) dimasukkan kedalam kotak transparan. Hal ini bertujuan untuk menyamakan konsentrasi yang terbaca oleh Ammonia gas meter dan Sensor MQ-137. Sensor MQ-137 dihubungkan dengan rangkaian dan Arduino UNO R3. Arduino UNO R3 dihubungkan dengan PC dengan kabel USB Arduino. ADC dari MQ-137 akan ditampilkan di monitor dan tegangan keluaran MQ-137 akan diukur menggunakan multimeter. 


\subsection{Pengujian Transceiver nRF24L01+}

Pengujian transceiver nRF24L01+ dilakukan dengan menguji pengiriman hasil pengukuran dan mengetahui seberapa jauh jarak pengiriman nilai pengukuran tersebut terkirim dari unit transmitter ke unit receiver. Hasil dari pengujian ini bertujuan untuk mengetahui kemampuan spesifik jarak tempuh pengiriman data transceiver nRF24L01+ dalam peranannya sebagai sistem telemetri nirkabel.

Karakterisasi transceiver nRF24L01+ melalui beberapa tahap berikut ini:

1. Rangkaiaan Arduino UNO R3 dengan transceiver nRF24L01+ dihubungkan dengan antarmuka adaptor. Transceiver nRF24L01+ memiliki 8 pin, yaitu pin CE, CSN, SCK, MISO, MOSI, IRQ, GND dan Vcc yang semuanya dihubungkan ke adaptor sesuai dengan pin masing-masing.

2. Pin adaptor akan dihubungkan ke pin digital Arduino UNO R3 dengan pin CE dihubungkan ke pin 9, pin CSN ke pin 10, pin SCK ke pin 13, pin MISO ke pin 12 dan pin MOSI ke pin 11. Rangkaian transceiver nRF24L01+ yang dihubungkan ke Arduino UNO R3.

3. Upload program karakteriasi Transceiver nRF24L01+ ke dalam software Arduino IDE pada komputer. Program di-compile terlebih dahulu untuk memastikan tidak ada terdapat kesalahan pada program. Apabila tidak ada kesalahan maka upload program sudah bisa dimulai.

4. Data pengiriman sebuah hasil pengukuran dari setiap unit dan mengetahui seberapa jauh jarak pengiriman data dapat dilihat melalui komputer. Rangkaian transceiver nRF24L01+ setiap unit yang dihubungkan ke Arduino UNO R3.

Gambar 3 menunjukkan terdapat 2 rangkaian yang dihubungkan ke dalam rangkaian arduino UNO R3, yaitu rangkaian sensor MQ-137 yang berfungsi untuk memantau konsentrasi amonia, dan rangkaian transceiver nRF24L01+ sebagai sistem telemetri nirkabel yang akan mengirimkan data konsentrasi gas amonia.

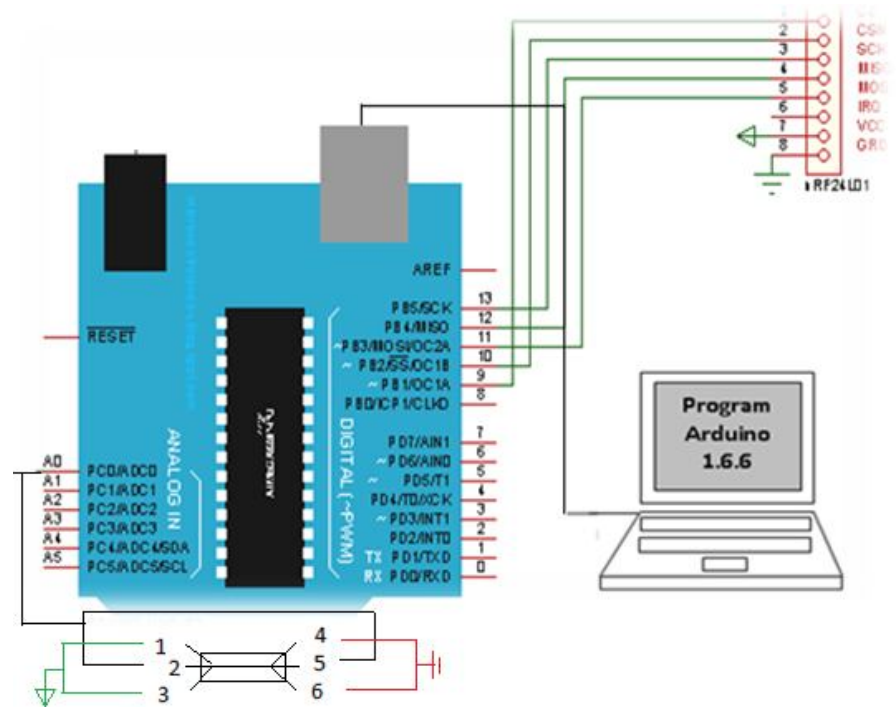

Gambar 3 Rangkaian Perangkat Keras Secara Keseluruhan Unit Transmitter

Pengujian transceiver nRF24L01+ ini dibagi menjadi 2 kondisi yaitu pengujian pada kondisi Line of Sight (LOS) dan Non Line of Sight (NLOS). Pengujian modul transceiver nRF24L01+ pada kondisi LOS dengan meletakkan unit transmitter dan unit receiver pada posisi yang tidak ada penghalang antara keduanya. Lokasi pengujian kondisi LOS ini dilakukan di bantaran sungai Banda Kali di daerah Simpang Haru kota Padang. Unit transmitter di suatu titik di tepi sungai dan unit receiver di tepi seberang sungai, dengan demikian posisi unit transmitter dan unit receiver berada pada dua titik tanpa penghalang.

Pengujian modul transceiver nRF24L01+ pada kondisi NLOS dilakukan dengan dua macam kondisi. Pengujian modul transceiver nRF24L01+ pada kondisi NLOS yang pertama 
dilakukan di Jalan antara halte belakang gedung Fakultas peternakan UNAND menuju Fakultas Ekonomi UNAND. Pengujian pada kondisi NLOS yang kedua dilakukan dengan memposisikan transmitter didalam ruangan sedangkan receiver berada di luar ruangan dilakukan di Laboratorium Elektronika dan Instrumentasi Jurusan Fisika Fakultas Matematika dan Ilmu Pengetahuan Alam sampai ke tribun di sekitar Fakultas Pertanian Universitas Andalas. Jarak antara transmitter dan receiver diukur menggunakan aplikasi Google Map.

\subsection{Perancangan Program Perangkat Lunak}

Perancangan sistem pengukur konsentrasi gas amonia yaitu pemograman bahasa $\mathrm{C}$ pada Arduino UNO R3 sebagai pengolah data sensor MQ-137, diperlukan kabel USB untuk interface antara Arduino UNO R3 dengan komputer yang terhubung melalui pin USB pada Arduino UNO R3 sekaligus sebagai sumber tegangan bagi arduino UNO R3. Hal yang paling penting dilakukan sebelum meng-upload program adalah memastikan jenis pin dan board pada menu tools sesuai dengan jenis arduino yang digunakan.

\subsection{Rancangan Sistem Telemetri Pengukur Konsentrasi Gas Amonia}

Gambar 4 menunjukkan proses pengiriman data pengukuran konsentrasi gas amonia ke unit receiver. Konsentrasi gas amonia akan diindera oleh sensor MQ-137. Udara yang diukur yaitu udara didalam kotak di dekat gelas ukur yang berisi amonia cair. Data konsentrasi gas amonia akan diproses oleh microcontroler ATmega328 yang berada di board Arduino UNO R3 dan ditampilkan melalui komputer. Data dari unit transmitter akan dikirim secara telemetri nirkabel dengan menggunakan transceiver RF24L01+ ke unit receiver.
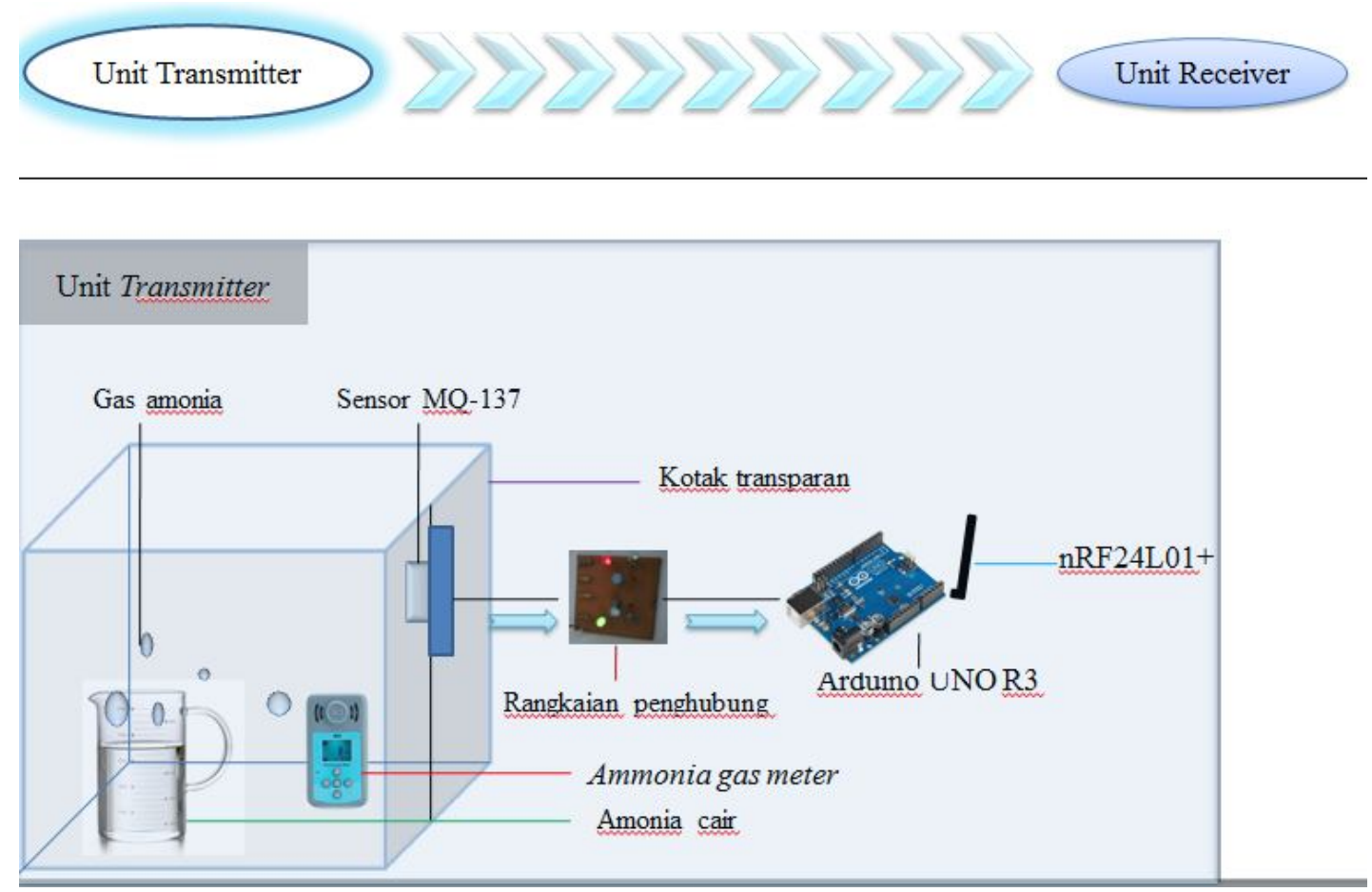

Gambar 4 Rancangan Sistem Telemetri Pengukur Konsentrasi Gas Amonia

\subsection{Analisis Data Pengukuran}

Teknik analisis data yang akan dilakukan adalah secara grafik dan secara statistik. Grafik berguna untuk memberikan hasil secara visual dalam menggambarkan hubungan dua variabel yang diperoleh dari pengukuran atau perhitungan. Analisis data hasil pengukuran merupakan proses untuk mengetahui tingkat ketelitian dan keakuratan suatu pengukuran. Ketepatan dari sistem dapat ditentukan dari persentase kesalahan antara nilai aktual dengan nilai yang terlihat. Persentase kesalahan dapat ditentukan dengan Persamaan (1). $Y_{n}$ merupakan nilai konsentrasi sebenarnya. $Y_{o}$ merupakan nilai konsentrasi yang terukur oleh alat yang dirancang. 


$$
\text { Error }=\left|\frac{Y_{n}-Y_{o}}{Y_{n}}\right| \times 100 \%
$$

\section{HASIL DAN DISKUSI}

\subsection{Hasil Pengujian Sensor MQ-137}

Pengujian sensor MQ-137 dilakukan ada dua tahapan. Pengujian pertama yaitu proses karakterisasi sensor MQ-137 dimana dilakukan perbandingan konsentrasi amonia yang terbaca pada alat pembanding dengan desimal ADC dan tegangan keluaran sensor MQ-137. Plot data tegangan keluaran terhadap konsentrasi gas amonia diperlihatkan pada Gambar 5. Fungsi transfer pada grafik memperlihatkan bahwa tegangan keluaran pada MQ-137 sebanding dengan konsentrasi amonia yang terukur pada sampel, dengan koefisien determinasi sebesar $R^{2}=$ 0,9461. Fungsi transfer yang didapatkan untuk sensor $y=0,0208 x+3,152$. Hal ini menunjukkan bahwa sensor memiliki sensitivitas sebesar $0,0208 \mathrm{~V} / \mathrm{ppm}$ dan offset sebesar $+3,152 \mathrm{ppm}$.

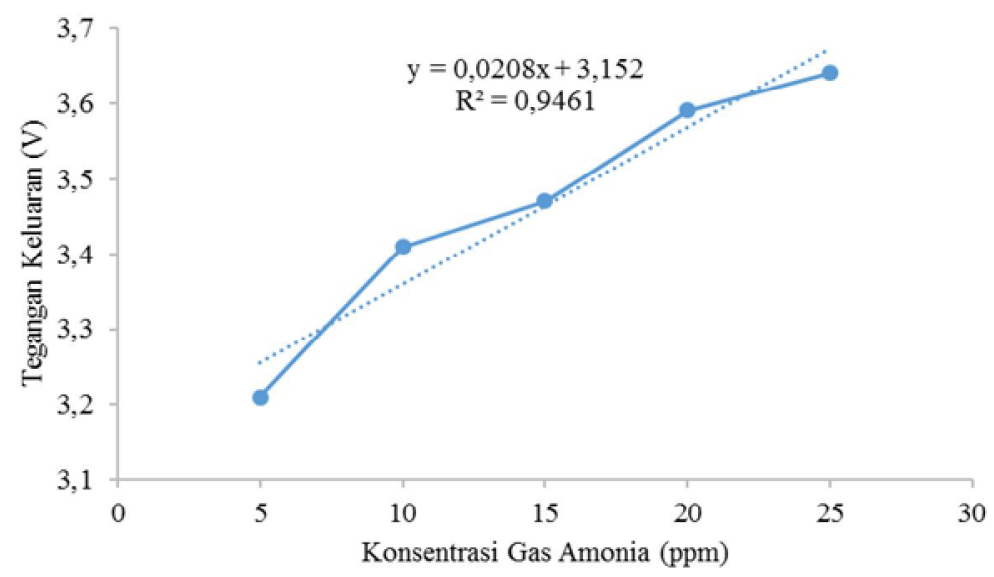

Gambar 5 Grafik Hubungan Tegangan Keluaran MQ-137 Terhadap Konsentrasi Gas Amonia

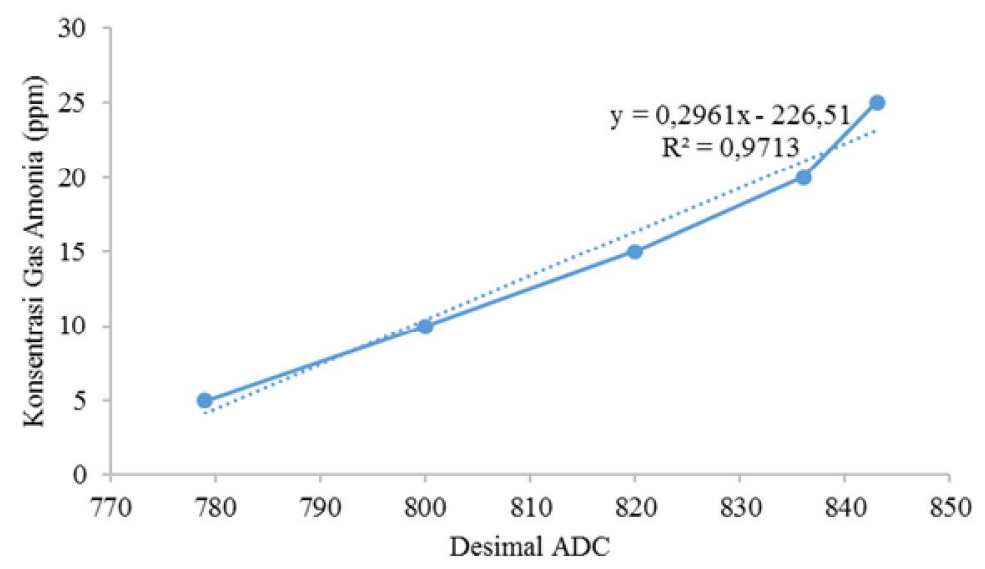

Gambar 6 Grafik Hubungan Konsentrasi Gas Amonia Terhadap Desimal ADC Pada MQ-137.

Gambar 6 memperlihatkan hubungan konsentrasi gas amonia terhadap desimal ADC pada MQ-137. Fungsi transfer konsentrasi gas amonia terhadap desimal ADC yang didapatkan yaitu $y=0,296 x-226,4$. Fungsi transfer yang didapatkan akan digunakan sebagai persamaan dalam program pada MQ-137 untuk mengukur konsentrasi gas amonia. Perbandingan konsentrasi yang terbaca oleh MQ-137 dengan konsentrasi yang terbaca pada Ammonia gas meter dilakukan setelah sensor MQ-137 dikarakterisasi dan fungsi transfernya dimasukkan ke dalam program yang ditanamkan ke Arduino UNO R3. Hasilnya diperlihatkan pada Tabel 1. 
Tabel 1 Perbandingan Konsentrasi Gas Yang Terukur Pada Rancangan dan Ammonia Gas Meter.

\begin{tabular}{cccc}
\hline No. & $\begin{array}{c}\text { Konsentrasi Gas Pada } \\
\text { Rancangan }(\mathbf{p p m})\end{array}$ & $\begin{array}{c}\text { Konsentrasi Gas Pada } \\
\text { Amonia } \text { Gas Meter }(\mathbf{p p m})\end{array}$ & $\begin{array}{c}\text { Error } \\
(\boldsymbol{\%})\end{array}$ \\
\hline 1 & 3,76 & 5 & 24,80 \\
2 & 5,24 & 6 & 12,67 \\
3 & 7,61 & 7 & 8,71 \\
4 & 9,98 & 8 & 24,75 \\
5 & 10,86 & 9 & 20,67 \\
6 & 11,16 & 10 & 11,60 \\
7 & 12,34 & 11 & 12,18 \\
8 & 13,23 & 12 & 10,25 \\
9 & 14,12 & 13 & 8,62 \\
10 & 15,30 & 14 & 9,29 \\
11 & 16,78 & 15 & 11,87 \\
\hline \multicolumn{5}{c}{}
\end{tabular}

Error rata-rata hasil pengukuran konsentrasi terhadap alat standar adalah sebesar 14.13\%. Hal ini menunjukkan bahwa sensor MQ-137 bekerja dengan cukup baik tapi belum memiliki nilai yang sama dengan pengukuran pada Ammonia gas meter. Hal tersebut terjadi akibat kabel penghubung kaki sensor dengan board PCB sedikit renggang sehingga mengurangi tegangan yang masuk ke sensor dan menghasilkan noise. Hasil pengukuran konsentrasi amonia oleh MQ-137 dapat mencapai angka 3,76 ppm. Hal ini tidak sesuai dengan datasheet MQ-137 yang mana jangkauan sensor ini hanya mencapai $5 \mathrm{ppm}$. Hal tersebut disebabkan oleh noise yang terjadi pada rangkaian saat pengukuran.

\subsection{Hasil Pengujian Modul nRF24L01+ Pada Kondisi LOS}

Pada pengujian ini sistem transmitter dilengkapi dengan nRF24L01+ sehingga data dapat dikirim dari unit transmitter ke unit receiver. Berdasarkan Tabel 2 didapatkan jarak maksimum pengiriman data sejauh 599 m pada kondisi LOS. Jarak tersebut tidak sesuai dengan datasheet nRF24L01+ yang memiliki jangkauan jarak $1000 \mathrm{~m}$ (Docfoc, 2016). Hal ini terjadi karena noise yang disebabkan oleh rangkaian transmitter. Hal tersebut akan menggangu nilai tegangan input pada transceiver nRF24L01+. Tegangan input pada transceiver nRF24L01+ yang telah diukur didapatkan $V_{i n}=4,78 \mathrm{~V}$. Nilai tegangan ini tidak sesuai dengan datasheet nRF24L01+ yang memerlukan $V_{i n}=5 \mathrm{~V}$ (Docfoc, 2016).

Tabel 2 Pengujian Modul Transceiver nRF24L01+ Pada Kondisi LOS

\begin{tabular}{ccccc}
\hline No. & Jarak $(\mathbf{m})$ & $\begin{array}{c}\text { Konsentrasi Gas } \\
\text { Pada Rancangan } \\
(\mathbf{p p m})\end{array}$ & $\begin{array}{c}\text { Konsentrasi Gas Pada Amonia } \\
\text { Gas Meter } \\
(\mathbf{p p m})\end{array}$ & Status Data \\
\hline 1 & 50 & 32,13 & 32,13 & Terkirim \\
2 & 100 & 32,72 & 32,72 & Terkirim \\
3 & 150 & 33,31 & 33,31 & Terkirim \\
4 & 200 & 33,61 & 33,61 & Terkirim \\
5 & 250 & 33,61 & 33,61 & Terkirim \\
6 & 300 & 34,50 & 34,50 & Terkirim \\
7 & 350 & 34,50 & 34,50 & Terkirim \\
8 & 400 & 34,79 & 34,79 & Terkirim \\
9 & 450 & 35,38 & 35,38 & Terkirim \\
10 & 500 & 35,68 & 35,68 & Terkirim \\
11 & 550 & 35,79 & 35,79 & Terkirim \\
12 & 599 & 36,86 & 36,86 & Terkirim \\
13 & $>599$ & 36,86 & - & Tidak Terkirim \\
\hline
\end{tabular}

\subsection{Hasil Pengujian Modul nRF24L01+ Pada Kondisi NLOS}

Pengujian modul transceiver nRF24L01+ pada kondisi NLOS lokasi pertama yaitu Jalan antara halte belakang gedung Fakultas peternakan UNAND menuju Fakultas Ekonomi 
UNAND dapat dilihat pada Tabel 3. Jarak tranmisi maksimum yang dapat dijangkau pada kondisi ini adalah $250 \mathrm{~m}$. Hal ini disebabkan oleh energi yang teratenuasi oleh pepohonan, tiang listrik, dan benda lainya selama propagasi gelombang sehingga energi gelombang radio diabsorpsi, direfleksikan, dihamburkan oleh penghalang-penghalang tersebut. Hal ini menyebabkan sinyal tidak mampu mengirimkan informasi pada jarak yang lebih jauh. Ketebalan penghalang-penghalang tersebut juga menyebabkan gelombang mengalami hamburan, pemantulan, penyerapan sehingga gelombang terganggu saat perambatan menuju receiver.

Tabel 3 Pengujian Modul Transceiver nRF24L01+ Pada Kondisi NLOS Lokasi Pertama

\begin{tabular}{ccccc}
\hline No. & $\begin{array}{c}\text { Jarak } \\
(\mathbf{m})\end{array}$ & $\begin{array}{c}\text { Konsentrasi Gas Yang } \\
\text { Terukur Pada Transmitter } \\
(\mathbf{p p m})\end{array}$ & $\begin{array}{c}\text { Konsentrasi Gas Yang } \\
\text { Terukur Pada Receiver } \\
(\mathbf{p p m})\end{array}$ & Status Data \\
\hline 1 & 100 & 35,57 & 35,57 & Terkirim \\
2 & 200 & 36,75 & 36,75 & Terkirim \\
3 & 250 & 49,34 & 49,34 & Terkirim \\
4 & $>250$ & 49,34 & - & Tidak Terkirim \\
\hline
\end{tabular}

Pengujian pada kondisi NLOS lokasi kedua dilakukan dari dalam Laboratorium Elektronika dan Instrumentasi Jurusan Fisika Fakultas Matematika dan Ilmu Pengetahuan Alam sampai ke tribun di sekitar Fakultas Pertanian Universitas Andalas. Hasil pengujian dapat dilihat pada Tabel 4. Jarak transmisi maksimum yang dapat dijangkau pada kondisi ini adalah $110 \mathrm{~m}$. Hal ini disebabkan oleh energi yang teratenuasi oleh dinding gedung, tiang koridor, dan benda lainya selama propagasi gelombang sehingga energi gelombang radio diabsorpsi, direfleksikan, dihamburkan oleh penghalang tersebut. Hal ini menyebabkan sinyal tidak mampu mengirimkan informasi untuk jarak yang lebih jauh. Ketebalan penghalang juga menyebabkan gelombang mengalami hamburan, pemantulan, penyerapan sehingga gelombang terganggu saat perambatan menuju receiver.

Tabel 4 Pengujian Modul Transceiver nRF24L01+ Pada Kondisi Lokasi Kedua

$\left.\begin{array}{ccccc}\hline \text { No. } & \begin{array}{c}\text { Jarak } \\ (\mathbf{m})\end{array} & \begin{array}{c}\text { Konsentrasi Gas Yang } \\ \text { Terukur Pada Transmitter } \\ (\mathbf{p p m})\end{array} & \begin{array}{c}\text { Konsentrasi Gas Yang } \\ \text { Terukur Pada Receiver }\end{array} & \text { Status Data } \\ \mathbf{( p p m )}\end{array}\right)$

\section{KESIMPULAN}

Berdasarkan hasil pengukuran yang diperoleh dan analisis data yang telah dilakukan pada penelitian ini, maka dapat disimpulkan bahwa sensitivitas sensor yang didapatkan sebesar $0,0208 \mathrm{~V} / \mathrm{ppm}$. Fungsi transfer tegangan keluaran terhadap konsentrasi gas amonia yaitu $y=$ $0,0208 x+3,152$ dengan koefisien determinasi $R^{2}=0,9641$. Fungsi transfer konsentrasi amonia terhadap desimal ADC yaitu $y=0,296 x-226,4$ dengan koefisien determinasi $R^{2}=0,9685$. Pengujian transceiver nRF24L01+ pada kondisi tanpa penghalang atau Line of Sight (LOS) dapat mengirimkan data dengan jarak transmisi maksimum sebesar 599 m. Pengujian transceiver nRF24L01+ pada kondisi dengan penghalang atau Non Line of Sight (NLOS) akan menyebabkan jarak transmisi maksimum berkurang karena perambatan gelombang mengalami atenuasi akibat adanya penghalang berupa benda-benda di sekitar proses transmisi dan ketebalan penghalang tersebut.

\section{DAFTAR PUSTAKA}

Fajriansyah, B., Ichwan, M. dan Susana, R., 2016, Evaluasi Karakteristik Xbee Pro dan nRF24L01+ sebagai Transceiver Nirkabel, Jurnal ELKOMIKA, Vol 4, No 1, hal 83-97, Institut Teknologi Nasional (ITENAS). 
Permana, H.A.N , Hayati Z., Pulungan Z., Supriatna, Suryana, Y., Mujahidin, S., Budiyono, 2011, Pengembangan Alat Deteksi Gas Pada Tambang Batubara Bawah Tanah Dengan Sistem Kabel dan Telemetri, Puslitbang Teknologi Mineral dan Batubara.

Pramono, J., Mardjoko, B.P., dan Susila, T., 2015, Perancangan Alat Telemetri Temperatur dan Gas Pada Gunung Berapi Secara Wireless, TESLA, Vol. 17, No. 1, Hal 88-104, Universitas Tarumanagara Jakarta.

Docfoc, 2016, 2,4G nRF24L01 Wireless Module $\mathrm{w} / \mathrm{PA}$ and LNA, http://www.docfoc.com/datasheet-wir020, diakses Agustus 2016 